\title{
1
}

BOOK REVIEW

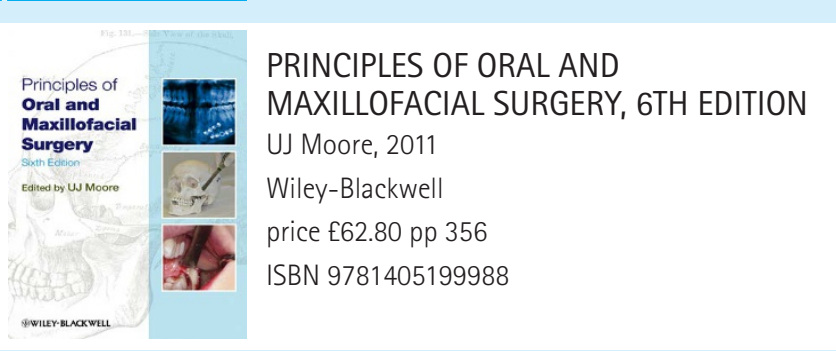

Historically, the vast majority of textbooks have been written and published in America and it goes without saying that these books are of fine quality. Becoming a specialist in oral surgery and oral and maxillofacial surgery in Britain commands an exceptional degree of training, the highest in the profession, and it is therefore appropriate and refreshing to acknowledge the work of a group of British oral surgery specialists, who authored this excellent book. Dr U. J. Moore has contributed heavily to the area of oral surgery and is involved in postgraduate teaching in Newcastle Dental Hospital and Royal Victoria Infirmary; making him a very credible editor of this latest edition.

The book is addressed to a wide audience, from undergraduate dental and medical students, through to general dental practitioners, oral and maxillofacial senior house officers, registrars and established specialists. The textbook has been correlated by a diverse group of clinicians, including: consultant oral surgeons, consultants and professors of oral and maxillofacial surgery, and consultant restorative dentists. First published over 40 years ago and now in its sixth edition, this book is thoroughly revised and reflects the latest technological developments in the field of oral and maxillofacial surgery.

The book is divided into 18 chapters. Topics include: patient assessment, human diseases, medical emergencies, pharmacology of oral surgery, the operating room, exodontia, pre-prosthetic surgery, surgical infection, odontogenic cysts, maxillofacial trauma, oncology, temporomandibular disorders, chronic orofacial pain and facial deformity. Throughout each chapter there is generous use of subtitles that compartmentalise the different themes and this is well supported by clinical photographs, diagrams, figures and tables. At the end of each chapter are suggestions for further reading, enabling the reader to acquire the relevant evidence base for points raised in the text.

Oral and maxillofacial surgery relies heavily on a multidisciplinary approach to manage the majority of cases; integrating elements of surgery, radiology, pathology and oral medicine. This is well supported in this textbook and certainly promotes synoptic learning; avoiding fragmentation of the speciality. The four chapters that cover exodontia are a particular highlight; covering principles of the surgical plan, routine extraction, complications and other more complex themes, including extraction of buried canines.

In summary, I would not hesitate to recommend this book to anyone interested in this field. It covers all the essential areas of oral and maxillofacial surgery, and provides a firm foundation for further reading. As a dental officer who wishes to embark on a career in oral and maxillofacial surgery, I am all too aware of the steep learning curve ahead; however, this book has become an excellent resource to start my preparations for this exciting transition.

L. Bovensiepen

\section{BDA surveys of associates and practice owners}

The British Dental Association (BDA) is currently surveying associates and practice owners across the UK to find out more about dentists' morale, motivation and job satisfaction. The survey of practice owners also seeks to learn more about practice investment and recruitment.

A sample of BDA members working in general dental practice has been selected to participate in these surveys; you may have already received an email inviting you to participate. Paper copies of the survey are also being sent out to those who are yet to respond. If you receive a paper copy please complete it and return it using the prepaid envelope by Friday 5 August.

Your participation will help to support the policy activity the BDA undertakes on behalf of the profession and will help us identify ways to improve dentists' working conditions. It will also inform the evidence we supply to the Review Body on Doctors' and Dentists' Remuneration (DDRB).

Those members who complete their survey by the deadline will also be entered into a prize draw to win a $£ 100$ Marks \& Spencer voucher.

If you have any questions or would like more information about this research, please contact the BDA Research Team at research@bda.org or call 02075355838 .

\section{Exciting history of dentistry event to be held in London}

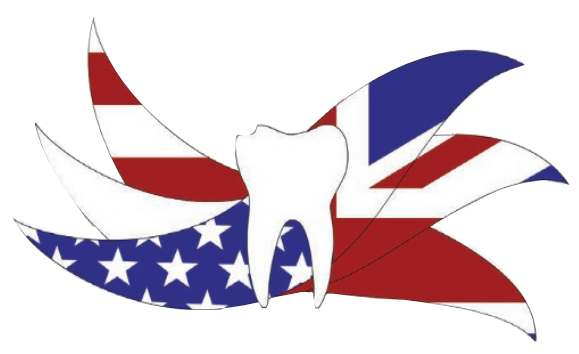

For the first time, the Lindsay Society for the History of Dentistry and the American Academy of the History of Dentistry are joining together to hold an event entitled 'Anglo-American Dental History Conference: Social and medical influences on dentistry 18th-20th century' on 8-9 October 2016 at the British Dental Association (BDA) on Wimpole Street in London.

A fascinating programme of lectures and events delivered by expert clinicians, medical and social historians will include Professor Colin Jones speaking on 'Teeth and smiles in the Age of Enlightenment'; Jelena Bekvalac speaking on the oral health of London past; and Dr Clare Jones discussing the cultural history of the toothbrush.

Registration for the event includes a Friday evening reception in the Hunterian Museum at the Royal College of Surgeons, a light lunch and afternoon tea each day.

For further information and to book for the event, visit https:// www.bda.org/lindsaysociety. 